\title{
381
}

3

y 1

I FI

CULTURE AND MANAGEMENT

OF OUR

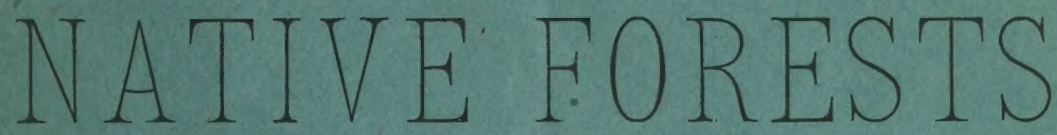

FOR DEVELOPMENT AS

TIMBER OR ORNAMENTAL WOOD.

$\frac{1882}{\text { Entered according to act of Congress, }}$

H. W. S. CLE V ELA N D. By H. W. S. Cleveliand.

SPRINGFIELD:

H. W. RoKker, Printer AND Binder.

1882 . 

T工圷

\section{CULTURE AND MANAGEMENT}
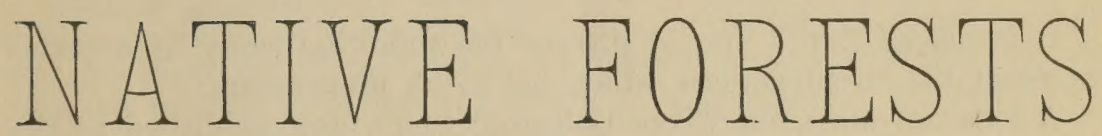

FOR DEVELOPMENT AS

TIMBER OR ORNAMENTAL WOOD.

H. W. S. C L E V E L A N D.

1882.

Entered according to act of Congress,

By H. W. S. Clegveland.

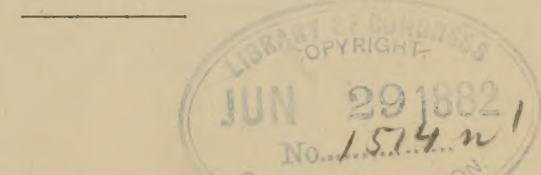

SPRINGFIELD:

H. W. Rokker, Printer and Bindek. 


\section{INTRODUCTION.}

It is proper that I should preface the following essay by a statement of the circumstances which led to its preparation.

A letter of mine, on "Tree Culture," which was published in the New York Nation of Dec. 1, 1881, elicited so many inquiries from such widely separated sections of the country, as to convince me that the subject was one of very general interest. In every letter I received the question was asked, "Where can I find any treatise or book of instruction on the management of our native forests ?" and I was forced to reply that I knew of no such book, and had been assured, on the highest authority, that there was no foreign work that was applicable to our wants. All that I had learned upon the subject had been from experience and observation, and I felt painfully conscious of my own ignorance of much that pertains to it. But the questions that were asked me by intelligent inquirers afforded in themselves sufficient evidence of a general want of recognition of some of the principles which experience had taught me were of essential importance in forest culture. These I have endeavored to set forth in the following essay, which I have had the honor of reading to a committee of the Massachusetts Legislature, and to the National Forestry Congress, at Cincinnati.

97 Washington street,

H. W. S. Cleveland.

Chicago, Ill,, May 1, 1882. 


\title{
The Culture and Management of our Native Forests, for Development as Timber or Orllamental Wood.
}

\author{
BY H. W. S. CLEVELAND.
}

Man's progress from barbarism to civilization is indicated by the degree of skill he has attained in the cultivation of those products of the earth which minister to his necessities and comfort. As long as the natural resources are sufficient to supply his primary wants of food and clothing, he will make no effort to increase them, and it is only as he is driven by the necessities of increasing demand and diminishing supply that he exerts himself to secure relief by artificial means.

The first efforts of the savage at cultivation are of the rudest description, and just in proportion as tribes and nations advance in numbers, power and intelligence, do they also gain in improved methods of tillage, in greater knowledge of the science of culture, and in better implements and machinery for its performance.

These are simple truths, which everyone will recognize. Their application to the subject of forest culture, lies in the obvious fact that it is not until a nation has reached mature age, and an advanced stage of civilization, that the native growth of wild forest proves insufficient for the increasing demand for timber, and the necessity of providing, by artificial culture, for an additional supply, begins to be felt.

We could hardly have a more striking illustration than is here afforded, of the adaptation of the provisions of nature, first, to the immediate necessities of existence, and subsequently to the development of the latent powers of the human race. The cereals and vegetables which are essential to man's daily support are of annual growth. Their culture is comparatively simple, and he soon learns that his very existence is dependent upon their renewed production with each recurring summer. The forests are equally essential to his further development, by furnishing material for the construction of houses and ships, and the countless implements by whose aid he attains to almost superhuman power. But the forest requires the lifetime of two or three generations for the full attainment of maturity. In the infancy of the race, the necessity of providing for such distant wants could not be foreseen.

Nature, therefore, as if she had been conscious that forest culture was too arduous an undertaking for primitive man, has furnished so abundant a supply, that no deficiency or necessity of economy is felt till the nation has acquired such a degree of intelligence as to be competent to the solution of the problem.

And this is the point at which we now stand, and which the older nations of Europe have long since passed, seeing plainly that our 
natural sources are well nigh exhausted, yet shrinking from the unfamiliar task of seeking to supply the deficiency by artificial means.

Many once powerful nations have dwindled into insignificance in consequence of their neglect of this lesson which nature imperatively demands that we should learn. Their fate should be to us a warning, as the efforts of the most intelligent nations of to-day should be to us an example, to save us from a like fate. The necessity for action is imminent, and can not be averted. The subject of the increasing demand and rapidly diminishing supply of timber throughout the country, has been so thoroughly discussed by legislative committees, both State and National, by agricultural societies and by able individual writers, that it would seem but a waste of time to bring forward the oft-repeated statistics in evidence of the danger that threatens us, and the urgent need of adopting measures of protection and relief.

Assuming, therefore, that my readers are familiar with the data which prove the necessity, I pass at once to the consideration of the means of averting the danger.

The only measure of relief thus far suggested with any definite prospect of success, is the planting of new forests. Much has been said, it is true, about the preservation of those that remain; but the words seem meaningless, in view of the fact that private property is beyond the control of the Government, and Congress declines even to grant means to prevent the destruction of that which still pertains to the public domain.

The planting of new forests is indeed an all-important work, which can not be too strongly urged, but we have not yet reached the period when it is likely to be successfully inaugurated, except, perhaps, in occasional instances by railroad or manufacturing companies, with a view to their own future wants. Individuals will not engage, to any great extent, in a work which demands the investment not only of a large amount of money, and the continuous expenditure of a great deal of labor, but also of a long period of time, which is the one form of capital of which we never have a surplus. It behooves us, therefore, to study rather more closely than we have heretofore done, the possibility of improving the condition of that which remains. The woods still standing contain a vast amount of available material which is susceptible of development in far less time than would be required for the planting and growth of new forests, our utter neglect of which furnishes one of the most striking proofs of our ignorance of forest culture.

No one can travel through any portion of the States east of the prairie regions, without being impressed by the fact that he is never out of sight of woodland. In fact, the chief cause of the prevailing apathy on the subject of forest planting, arises from the fact of the great abundance of groves and extended forests, which convey the impression, in spite of the assertions of staticians, that there is still enough wood growing to supply the place of that which is removed.

The Duke of Argyle, in the interesting sketch of his trip through the States, published after his return to England, says emphatically that nothing in the aspect of the country surprised and impressed him so much as the great amount of wood still remaining, and everywhere giving beauty and variety to the landscape; but he 
added that it was everywhere the beauty of the wild wood, which never bore any evidence of culture or effort to increase its value by artificial development.

"I saw nothing (he says) that could be called fine timber, and no woods which showed any care in thinning, with a view to the production of such timber in the future."

Such a criticism is not surprising from one who, like most country gentlemen of England, is familiar with the process of forest culture, but it certainly is surprising that, with all our boasted intelligence, we still remain practically insensible to the fact that, while almost every tract of woodland contains a large percentage of such trees as are most valuable for timber, already well advanced in growth, and susceptible, by judicious management, of being developed into proper form and size for use in far less time and at far less cost than would be required for the planting and growth of new forest; yet, if left to themselves, not one tree in a thousand will ever be fit for anything better than fencing stuff or fuel. Vast resources of wealth are lying latent and running to waste in our woodlands, and we stand stupidly unconscious of the fact that its development requires simply the application of the intelligent culture we bestow on all other crops. In many instances, it is true, the native woods have been so long neglected, that they are past redemption, but there are, nevertheless, large areas of continuous forest, and smaller groves and woodlots in every section of the country, now yielding no revenue, which might, by proper annual thinning, pruning and culture, be developed into timber forests of very great value, while yielding an annual crop of firewood in the process.

Where shall we find, or how shall we create, the men who are competent to the work? To judge from invariable practice, our people seem not only to be ignorant of the first principles of forest culture, but unconscious even of the possibility of its application to the development of our native woods. The fact of such prevailing ignorance rests not alone upon negative evidence. We have positive proof in abundance in the attempts which we often see at the "improvement" of a piece of woodland when it is appropriated as the site of a residence. It is hard to conceive of anything more dismal and forlorn than the average result of the effort to impart a homelike aspect to such a place; the dwelling, with its "span new" expression, standing in the midst of a multitude of tall poles, with tufts of leaves upon their tops, looking like fowls stripped of their feathers, and the bare ground fretted everywhere with freshly upturned roots, the sole remnants of the wild shrubbery which has been ruthlessly exterminated.

In order to a comprehension of the principles of healthy forest growth, let us consider some of the processes of nature, and learn from them her requirements.

If we plant the seed of a maple, chestnut, linden, oak or ash tree by itself in the open ground in suitable soil, and suffer it to grow without molestation, simply guarding it from injury, we shall find that the first act of the young plant is to send out broad leaves, which serve among other purposes to shade completely the stem, 
and the ground immediately around it in which the roots are growing. As the tree grows, it preserves a symmetrical shape, the limbs spreading and the trunk increasing in size, in proportion to its height, but always preserving the condition of keeping the trunk and the ground for a considerable distance around it, in the shadow of the foliage till mature age, when the roots have penetrated to such a depth as to be safe from injury, and the trunk is protected by thick layers of cork like bark, which safely guards alike from heat and cold the inner layers and young wood in which the sap is performing its functions.

Such are the conditions to which nature adheres, if not interfered with by accident or design, and such, therefore, we may be sure, are those best adapted to healthy and vigorous growth. The fact that they are continually violated with apparent impunity, serves only to show the wonderful power of nature to supply deficiencies, and adapt herself to circumstances, but in artificial culture, we should aim as nearly as possible to imitate the course she would pursue if unimpeded.

The requirements of nature are of course the same when trees are growing together in a forest, as when they stand singly, but the conditions of growth are so changed that the end is attained by entirely different means.

If we enter a tract of wood land, covered with a hard wood growth of an average height of thirty or forty feet we find it composed almost exclusively of trees which have run up to a great height in proportion to the spread of their limbs. The largest and oldest of them may have had some lateral branches which are now dead, but the younger growth will consist only of tall, slender stems, without a branch or leaf except near the top. It will be difficult, perhaps impossible, to find a single tree possessing sufficient symmetry of form to be worth transplanting for ornamental use. A little reflection will serve to convince us that this form of growth, so different from that of the single tree in the open ground, is the natural result of the action of the same rules under changed conditions.

When a young wood first springs up on open ground, each tree begins to grow as if it were alone, sending out lateral branches and preserving its just proportion. But whenever these laterals meet and mingle with each other, they shut out the sunlight from all below, and thence forward all lateral growth must cease, and each individual is struggling upward to keep even with its neighbors and secure its share of the sunbeams which are essential to its existence, and which can only be had at the top. It thus becomes forced out of all just proportions in the effort to keep even with its fellows. The conditions of keeping the trunk and roots in the shade, however, are even more rigidly adhered to than in the case of the single tree, growing by itself, for the whole area of the wood is shaded, and, moreover, the trees on the edges of the wood, if not interfered with by men or cattle, will be clothed on the outer side with limbs and foliage, elear to the ground, so as to check the free passage of the winds whose drying influence upon the soil is even more active than that of the sun. 
If we examine more closely we shall find that nature adapts herself to these changed conditions, and avails herself of whatever advantages they afford.

The single tree when growing by itself sends its roots deep into the ground in search of the moisture which cannot be had near the surface, and thus, when it reaches mature age, it draws its supplies from sources beyond the reach of temporary changes, and, moreover, secures so firm a hold upon the ground that it suffers no injury from the storms that assail it, but fearlessly stretches forth its arms as if to challenge the gale.

In the woods, on the contrary, the surface soil never becomes parched or heated, but maintains an even degree of temperature and moisture in consequence not only of the exclusion of the sun and winds, but of the deep mulching of leaves which annually cover the ground and keep it moist, while, by their decomposition, they form a rich mould comprising all the ingredients of vegetation.

If we dig only a few inches into this mould we find it everywhere permeated by fibrous rootlets emanating from larger roots, which under these circumstances have kept near the surface where they draw nourishment from the rich material there provided. If the single tree in the open ground had tried to live by such means, it would speedly have perished for want of nourishment, or would have been uprooted by the winds as forest trees are liable to be when left alone in a clearing.

In the woods the necessity no longer exists of sending the roots to a great depth either in search of nourishment or for support against storms, and nature always adapts hereself to circumstances and attains her ends by the simplest and most economical means.

If we now consider the facts I have stated, which anyone can easily verify for himself, we shall find that all the essential principles of tree culture are comprised within their limits, and by their rational observances we may secure healthy and vigorous trees, and develope at will either such forms as will fit them for timber or for ornamental use.

The five trees I have cited-maple, chestnut, linden, oak and ash -are among the most common and yet the most valuable of our forest trees, and may be taken as representatives and proper illustrations of the facts I am stating. Either of these trees, if growing by itself in proper soil and undisturbed by other than natural influences, will attain, at maturity a height of seventy or eighty feet, with a spread of limb equal in diameter to its height, and a trunk of such massive proportions as leaves no room for apprehension of inability to uphold the wilderness of foliage it has to support. But these same trees, if growing in a wood, will send up a slender stem, straight as an arrow, fifty, sixty or seventy feet without a limb or a leaf, till it reaches the average height of its fellows, and sends out its tufts of foliage to secure the benefit of every sunbeam it can catch.

We see therefore, that if we wish to form a beautiful and symmetrical tree, or a grove of such, composed of individual specimens of majestic and graceful proportions, we must allow it free access, to sun and air, with full power of expansion on every side. While young, however, the growth will be more vigorous and healthy, and 
we can develop the desired forms more easily and sucessfully, by leaving a much greater number of trees than are eventually to remain, and removing from year to year all which are near enough to the final occupants to check or impede their full development.

If, on the other hand, we wish to develop the trunk or bole for use as timber we must plant, or suffer the trees to grow more thickly together, and thus extend its trunk longitudinally by forcing it to ascend in search of the sunlight on which its very existence is dependent. The indigenous growth, however, is always a great deal too thick for successful development. The trees are so crowded that many of them perish in the struggle, and those which survive are drawn up into such spindling proportions that not one in a hundred ever attains the dignity of timber, whereas by proper and reasonable thinning, and judicious culture and pruning of the trees selected for final retention, every acre of woodland might be made to yield an annual crop of fire-wood, and all the while be growing timber which eventually in many instances might be worth more than the land itself; or by a different process of management may be converted into a grove of majestic and graceful, ornamental trees.

The proper performance of this work constitutes the most important part of forest culture and for want of the knowledge of how it should be done, or from ignorance of the possibility of its application to our native forest, a vast area (in the aggregate) of woodland is running to waste; yielding no revenue and promising nothing better in the future than fire-wood, of which a very large proportion is yet susceptible of redemption and conversion into timber of great value at far less cost of time and labor than would be required for the planting and rearing of new forests, while the very process of development would be yielding an annual income instead of demanding large outlays.

Travel where we may we are never out of sight of forest, and every wood lot is a mine of wealth waiting only the application of intelligent labor for its development. In almost every tract of woodland may be found more or less of the trees I have named and in many places also hickory, walnut, butternut, elm, cherry, beech and other valuable timber trees, mingled with a great variety of those which are worthless, or fit only for fuel. In some cases they are past redemption, having been so long neglected that they have run up into mere thickets of hooppoles. Young growth may everywhere be found, however, which are in condition to be taken in hand, and in almost all cases the work of thinning, and pruning may be entered upon with a certainty of profitable results if wisely and perseveringly conducted.

The work of thinning, as ordinarily conducted in the occasional instances in which on any account it has become desirable, is entrusted to mere laborers, who have no regard for the natural conditions which are essential to healthy growth, and which can not be suddenly changed, without serious injury to the trees that are left.

All the small growth of shrubs, such as hazel, cornel, dogwood, elder, shad-bush, etc., is first grubbed out and destroyed under the general term of "underbrush," and this not only throughout the interior of the wood, but round its outer edges where such shrubbery is apt to spring up in thickets, which serve the very important pur- 
pose of preventing the free passage of the wind over the surface soil of the interior, besides adding incalculably to the beaty of the wood, as seen from without by connecting the line of foliage of the trees, with that of the sward below, and presenting a living mass of verdure. The trees which are considered most desirable to preserve, are then selected, and all the rest at once removed. Finally the leares are carefully raked from the surface and carried off or burnt.

Sun and wind now have free access to the soil, and it rery soon becomes parched and dry. The fine rootlets near the surface, which have heretofore been preserved by the never-failing moisture of the rich mould under its mulching of leaves, are converted into a mass of wiry fibres, no longer capable of conveying nourishment, even if it were within their reach. And while the means of supply are thus reduced, the tall, slender trunk, through which the sap must ascend to the leaves, is now exposed to the free action of the sun and winds. Now I do not presume to say, that evaporation can talie place through the bark, but the provisions which nature makes to guard the inner vital tissues, from the effect of the sun's rays indicate beyond all question, that they are in some way injurious. I have elsewhere shown that in the case of the single tree growing by itse?: the trunk is always shaded by the spreading foliage, when suffered to retain its natural form. In the forest, the trees shade each other, and thus effect the object by mutual action. But now let une call vour attention to another provision of nature which few people observe, but the meaning of which is too obvious to be mistaken. If we examine the bark of an oak, elm, chestnut or maple, of mature age, which has always stood by itself, exposed to the full influence of atmospheric changes, we find it to be of great thicliness of very rugged character, and of a cork-like consistency, all of which characteristics malie it the best possible non-conductor of heat or cold that can be imagined, under the protection of which the living tissues are safely kept from injury through the burning heat of summer and the intense cold of winter.

Now go into the forest where the trees shade each other, and wind and sun are excluded, and you will find that the bark of the trees, is smooth and thin in comparison with that of those in the open ground.

Natrue never wastes her energies needlessly, and the trees in the woods do not require the thick coat of those that are exposed. But the effect of suddenly admitting the sun and wind upon them is precisely the same as that of exposing any portion of the humau skin which had heretofore been clothed. It is to guard against injury from this source that experienced tree-planters, when remoring large trees from the woods, are accustomed to swathe the trunlis with ropes of straw, which is a rational process, yet it is by no means uncommon to see the reverse of this action. I have seen. during the past winter a great many rery large fine trees planted on the best avenues in Chicago, at a cost of certainly not less than fifty dollars each, from the trunks and large limbs of which all the rough bark had been carefully scraped, leaving only a thin, smooth covering over the inner tissues. This is as if a man should prepare for unusual exposure to heat or cold by laying aside all his clothing. 
Few persons, even among those whose business is tree culture, as fruit-growers and nursery men, have any just conception of the value of thorough mulching, as a means of promoting the health and vigor of growing trees. In fact, such a mulching of the whole ground as nature provides in the forest by the annual fall of the leaves, may be said to be unknown in artificial culture, so rarely is it practiced, yet its immediate effect in promoting new and vigorous growth is such as would seem almost incredible to one who had not witnessed it, and affords one of the most beautiful illustrations of nature's methods of securing the most important results by such simple and incidental means that they escape our notice, though going on right under our eyes from year to year.

Of course the richest food for plant consumption is in the soil near the surface, but if that soil is subjected to alternations of temperature and moisture, sometimes baked in clods, and at others reduced to the consistency of mire, no roots can survive the changes. In the forest, as I have elsewhere said, these changes are prevented by the shade of the foliage and the mulching of fallen leaves. The rich mould of the surface soil maintains an even temperature, is always moist, and is everwhere permeated with fibrous roots drawing nourishment from the rich sources which surround them, and this process may be artificially imitated, and the same results attained, by mulching, if properly done. It does not suffice to pile a few inches of straw or manure around each tree for a short distance from the trunk. If the tree stands singly, at a distance from others, the mulching should extend on every side beyond the spread of its branches; and in the ease of an orchard, or young wood, the surface of the whole area it occupies should be covered with leaves, straw, shavings, chip-dirt, tan-bark, or whaterer material is most available, to a depth of several inches. I first learned the value of the process when a young man, on a coffee plantation in Cuba, where a portion of the hands were constantly employed in collecting refuse vegetable matter of all kinds, and spreading over the whole ground between the rows of the coffee bushes, to such depth as served to keep the surface cool and of even temperature, and also to prevent the growth of grass and weeds and thus supersede the necessity of ploughing between the rows.

Afterwards, when engaged in fruit culture in New Jersey, I prac. ticed it in my vineyard and orchards with most satisfactory results, of which an account was published more than thirty years ago, in the Horticulturist, then edited by A. J. Downing.*

The trees and vines responded at once to my efforts in their behaif by such increased luxuriance of growth that it was easy to distinguish the portions that had been mulched as far as they could be seen, and, on digging into the surface soil under the mulching at any point, I found it filled with fibrous roots precisely as is the case in the leaf mould in the woods. No fruit-grower who has once tried this experiment will ever after forego the advantages it offers, and I have spolien of it thus at length from the obriously rital importance of its bearing on forest culture. A moment's reflection will show that in the opening and thimning of native wood which had grown thickly together, a heary mulching of such portions of

*Horticulturist, Vol. 3, p. 113. 
the ground as may unaroidably become exposed may be of most essential service in preserving the health and rigor of the trees that are to be retained.

It is difficult to lay down specific rules by which a novice could be guided in the work of opening and thinming out the wood of a native forest, except by fully impressing him with the importance of preserving, so far as is possible, the conditions which nature shows to be the most favorable to vigorous growth, and proceeding very cautiously when it becomes necessary to cliange the relative proportions of the influences which affect the vitality of the trees. The age and condition of the wood at the time the work is begun, are, of course, important elements for consideration. If the growth is not more than ten or fifteen years, and the trees have not sprung up so thickly as already to have become a mere thicket of hooppoles, but have preserved a reasonable degree of symmetry, its management can be much more easily controlled than if it has attained a more mature age, and especially if the object is to create an ornanimtal grove composed of fine specimens of indiridual trees, a process by which the value of desirable residence sites in the vicinity of cities or large towns might often be very greatly increased.

Whether this be the object, or the development of timber, the first thing to be done is to select and place a distinguishing mark upon every tree which is ultimately to be retained. Then remove at first from its immediate vicinity only those which are actually crowding it, or impeding its growth by shading or interfering with its foliage. Those which simply shade the trunk or the ground around it are serring a useful purpose, and should not be disturbed. Indeed, if it is found that the necessary removals involve much increased exposure of the surface soil around the tree, it should at once be covered with the mulching of sufficient depth to prerent the possibility of its becoming heated and dry. All other sources of danger to the health of the trees are insignificant in comparison with that of the rude check they are liable to receive from sudden exposure of the trunlis and surface roots to the influence of the sum and wind, from which they have heretofore been protected, and to which they can only become accustomed by a gradual change.

The next year it will be found that the tree has gladly availed itself of the opportunity for expansion, and has spread its limbs to fill the vacant space around it, so that more trees must now be removed, while the increased mass of foliage it has developed renders it less liable to suffer injury from their loss.

The removal of the undergrowth of shrubbery, should be very cautiously conducted, and in no case should it be removed from the outshirts of the wood, which should everywhere be left with as dense a growth as possible, to prevent the entrance of the winds.

The sirocco-like wind from the $\mathrm{S}$. W., which often blows with great violence for days together, especially in the spring and early summer, when the trees are full of sap, and the young shoots and leaves are tender and sensitive, is the one from which most danger is to be apprehended. The merely mechanical injury it intlicts upon the spray and foliage is often serious, but its worst effects are due to its absorption of moisture and vitality. 
All experienced nursery men and fruit-growers, have learned to dread its exhausting influences especially, upon grape vines and other broad leaved plants, and they too are aware of the fact, which comparatively few ordinary observers seem to have noticed, that its effects in giving a generial trend of the spray and branches of trees in exposed situations towards the N. E., is so marked that no one who has learned to observe it, need ever be long at a loss to know the points of the compass in any parts of the country.

The fact, however, that we have it in our power to guard against the evil effects of this wind by artificial means, is not so generally known as it should be, and it was only after many years observation and experience that I came to a full realization of certain facts in comnection with its action, which bave a most important bearing upon the question of forest culture.

I became aware, many years since, that many shrubs, trees and plants would grow and thrive at Newport, R. I., and at Yarmouth, Nora Scotia, which in the interior were only found much farther south, and would certainly perish if removed to the latitude of those towns. The reason assigned in both cases was the warming influence of the neighboring gulf stream, which seemed a plausible explanation in which my faith remained unshaken for years, until I went to Chicago, where I found it was impossible to grow many of the finer fruits, and some of the forest trees which elsewhere are found in much higher latitudes. Neither peaches or grapes can be grown at Chicago, or at any other point on the western side of the lake without artificial protection, and the native growth of wood is very meagre, and many varieties which elsewhere are found much farther north, as the beech and the bemlock cannot be grown; yet the eastern shore of the lake, only sixty miles distant, has no superior in the whole country as a fruit growing region. Peaches, grapes, strawberries, etc., grow most luxuriantly anywhere on that shore up to the northern extremity of the lake, three hundred miles north of Chicago, and every variety of forest tree indigenous to the country is found in the best condition of vigorous health.

There is no gulf stream to account for this difference, but the relative position towards the lake of the whole extent of its fruitful shore is the same as that of Newport and Nova Scotia towards the ocean. In both cases the S. W. wind reaches the shore after passing for a long distance over water, and instead of burning and exhausting vegetation with a breath of fire, it comes laden with the moisture it has gathered up in its passage, and brings health and strength upon its wings, instead of disease and death. Further reflection served to convince me that the rule was susceptible of much wider application, and serves to explain the different vegetation of the eastern and western shores of great continents in the same parallels of latitude. Central Spain and southern Italy the lands of the orange and grape are in the same latitude as Boston, and going west on the same parallel to California, we again find onrselves surrounded with fruits and plants which in Boston ean only be grown under glass. Continuing our western flight across the Pacific, we find the flora of Eastern Asia to bear, in many respects, a striking resemblance to that of Eastern America. 
These facts have certainly a very important bearing upon the question of forest culture. They prove that the S. W. wind of spring and early summer is perhaps the worst enemy we have to guard against, and also that its deleterious influences are neutralized when it passes over a large body of water. It is comparatively rare, howerer, that a situation can be secured affording that advantage, and the question naturally arises, are there no other means of protection? I am happy to have it in my power again to summon nature as a witness that such means are within our reach.

I have said that the beech would not grow near Chicago, a fact which I was very reluctant to admit on first going there, and was only fully convinced of its truth by witnessing repeated failures, and the eridence of reliable nurserymen who had tried in vain to preserve it. Yet after I had long been satisfied that it was idle to attempt its culture, I was one day amazed, while surveying in the woods a few miles from the city, at coming upon a little group of beech trees comprising some twenty or thirty in all, of mature size and in full health and vigor. On examining the situation, to discover, if possible, an explanation of the phenomenon, I observed first that they stood in the bottom of a ravine so deep that their tops were scarcely even with its banks, while the wood which surrounded them extended more than a mile to the S. W., so that they were completely sheltered from the effects of the wind from that quarter. I have never been able to find or to hear of another beech tree anywhere in that region, and can only account for their presence by supposing the seed to have been brought from a distance by birds, probably crows, jays or wild pigeons, and dropped accidentally on a spot, which proved to be a "coigne of vantage," where they were safe from the enemy. The evidence thus afforded of the value of a screen on the S. W. side, should not be lost upon those who are selecting sites for orchards, or vineyards, and shows the importance when thinning a wood, of leaving whatever shubbery or foliage there may be on that side to arrest the progress of the wind.

The work of pruning the trees which are to be preserved for timber involves a careful consideration of the principles I have set forth, apart from the judgment required for the skilful performance of the mere manual labor. The object in view being the development of the bole, it is important to remove any limbs which threaten to become its rivals in size, if any such have become established before the work of improvement began. But after the trunk has attained the desired height, it is on all accounts desirable to develope the largest possible mass of foliage, because the making of wood can only be effected by the elaboration of the sap, which is the work of the leaves.

If one is rearing a new forest, in which the trees have been under his control from the time of planting, it must be the result of his own ignorance or negligence if he has failed to secure such forms as he desired, since it is easy to direct the growth of young trees, and prevent them from running into extravagances, which will unfit them for service as timber. And not unfrequently we may find a young wood of indigenous growth, which may be taken in hand and wrought into such shape that its future progress can be easily directed. But, for the most part, in woods that have been suffered to 
run wild till they have approached maturity, a good deal of shilful pruning will be required to bring the individual trees that are to be preserved into such form as will give them most value. Nothing but practice and careful observation can confer this power. The little treatise of DesCars on the pruning of forest and ornamental trees, translated by Mr. C. S. Sargent, of the Arnold Arborctum, and published by A. Williams \& Co., of Boston, (price 75 cents) contains full and explicit illustrated directions for all the manual worls of pruning, and is invaluable as a guide to the novice, and a work of reference to experienced foresters. But mere manual shill in the performance of the work will be of little avail without the application of a thorough knowledge of the principles of tree growtl, and a strict compliance with the requirements of their nature.

If our agriculturists will but apply to the management of their forests the same intelligence with which they direct the culture of other farm crops, they will find an equally ready response to their efforts. The farmer who should leave his field of corn or potatoes to shift for itself, or suffer his cattle and hogs to ramble: through it at will, wonld be justly sneered at by his neighbors and punished by the loss of his crop-and trees have no more capacity for self-management than corn or other vegetables, and are quite as ready to protit by judicious culture, and to yield returns corresponding to the care bestowed upon them. They are not liable to be utterly destroyed, as corn is, by the inculsions of live stock, but they do suffer serious injury from the trampling and rooting up of the ground. I have seen beautiful groves of oalis in Iowa full of dead and dying trees, and, on asking the cause, have been told that the native woods "can't stand civilization," but always die out when cattle begin to run in them; and I am told that, in Fentucky and elsewhere in the South, the young growth is found to contain only the inferior varieties of oalss, as the swine running in the woods seek and greedily eat the acorns of the white oak, on account of their superior sweetness. Has anyone ever estimated the cost of raising hogs on such food?

I have endeavored, in the preceding pages, to confine myself to the special features of forest growth which need to be regarded in the effort to develop and improve a native wood, wherever it may be. The planting and culture of an artificial forest is quite another affair, and I have made no allusion to it because my special object has been, if possible, to urge the fact, and arouse attention to it, that we still have vast resources of latent wealth on every side, susceptible of development by proper management, which we are everywhere suffering to run to waste. The work of planting and rearing artificial forests can not indeed be urged too strongly, and there is no danger of its being overdone. But the conviction of its necessity can be more readily and forcibly g. impressed upon the popular mind by an illustration of the possipilities of forest culture, when applied to our native woods, than by any other means. The need of further progress by artificial planting will speedily become obvious, and will follow in natural course.

It has been asserted, and with truth, that it is idle for us to establish schools of forestry, because there is no demand for foresters, and consequently no stimulus to the acquirement of a linowl- 
edge of the theory and practise of the art. It will be time enough to establish such schools, it is said, when we have evidence that there are people who desire to avail themselves of the advantages they offer, and that will not be till there is a demand for the services of those who have done so. This is true, so far as it goes, but the next consideration is, how to create the demand. There was no demand a few years ago for telegraph operators, and when I was a boy there was no demand for railroad employés, for there were no railroads. How was the demand created? By showing the importance of the results. Think of the time and labor expended by Morse and his associates before they could get permission to demonstrate the value of the electric telegraph by a line from Washington to Baltimore. No general interest was felt in the scheme till its advantages were thus made manifest, because there was no realizing conviction of its truth. And to-day we are in a similar position in reference to the question of forestry. The impending danger of the diminishing supply of timber is acknowledged by all who are familiar with the subject, but there is no realizing sense of it in the popular mind, and there is a want of confidence in the practicability of any of the proposed measures of relief. The first and most important thing to do, therefore, is to stimulate popular interest by showing what can be done. To create a popular demand of any kind, it is essential first to demonstrate the value of its object. The men who are familiar with forest culture, know, as well as Morse knew the capability of the telegraph, that the wealth of the nation may be enormously increased by the proper development of the native woods already standing, but they can point to no evidence of the truth of their assertion, and the fact that it has not been done is regarded as proof of its impossibility. There is no such thing in the country as an illustrative example of what may be accomplished by timber culture, and very few of our citizens who visit Europe can appreciate the works which have there been achieved. They go abroad to study works of art, with the idea that we have nothing to learn in regard to natural productions, and the comparatively small number who grasp the conception of the grand possibilities of development which our forests offer to the exercise of such artificial culture as may there be seen, can do no more on their return than express their convictions and urge the importance of acting upon them. This they have done for many years past, but they have not succeeded in arousing such a popular conviction of the necessity as should enforce the action of their representatives to the point of making needful provision. The enormous and costly scale on which the work of planting new forests must be undertaken, in order to be effective, seems to throw a damper upon every effort to bring it to pass.

If every owner of a wood lot could be convinced that its value might be enormously increased by a process which, so far from ?emanding an outlay, would add to his annual income, it would not be long before farmers would consider it as derogatory to their reputation to leave the forests in the wild condition they now are, as they would to have a field of corn presenting a similar appearance of slovenliness. To produce such conviction the truth must be demonstrated in actual practice, and the cost of such demonstration 
will be but a trifling price to pay for the returns it will bring. Let any State or city select a tract of woodland at some easily accessible point, and put it under a proper course of management, as an experimental forest, and it would very soon excite an interest which could not fail to increase. A portion of it should be suffered to remain in its original, unimproved condition. Another part should be improved as "open park," for the best development of individual trees in their fullest natural capacity of dignity and grace, and a third portion should be devoted to the production of timber by the process of thinning, pruning and proper culture. The progress of development could then be seen and watched from year to year in all its stages, and the demonstration thus afforded would touch the interest of every owner of a wood lot. The process would soon begin to be imitated, a conviction of the value and importance of a knowledge of forestry would become established in the popular mind, and the demand for the services of those who had acquired it would lead to a demand for the means of acquirement, and thus the schools of forestry would be called into existence by the natural course of events.

The inauguration of such an experimental or illustrative forest as a means of exciting public interest is surely an object that is well worthy the consideration of legislative and municipal bodies, or of corporations whose interests are connected with this form of national wealth. The cost would be insignificant in comparison with that of planting and maintaining new forests, and the spur of personal interest would incite such general action as would add incalculably to the wealth of every State without further outlay than the cost of demonstration.

It is of course desirable that the experimental forest should be as conspicuous and easily accessible to the public as possible, for which reason the vicinity of a city would seem the most appropriate point. And municipal bodies would be justified in making a liberal appropriation for the promotion of such an object, since it would certainly constitute, for great numbers of people, one of the principal attractions of the city. The beneficial results which would follow, however, would add so largely to the substantial wealth and power of the State that its main support should be derived from legislative rather than municipal action.

It is not, however, my province to discuss the means of effecting the work, beyond this general suggestion.

I have aimed only to convey a conception of the rich resources which nature has placed at our disposal, if we choose to avail ourselves of her offer.

I have made no statement in regard to forest growth which will not be recognized as true by all who are familiar with the subject, and all such persons will endorse my statement that, practically, the rules which govern the process are universally ignored.

I have pointed out what I conceive to be the readiest means of awakening public attention and creating such general interest as will insure reform, and I leave to other hands the task of arranging the laws which must govern its execution. 

